Article

\title{
Coping Strategies and Anxiety and Depressive Symptoms in Young Adult Victims of Cyberstalking: A Questionnaire Survey in an Italian Sample
}

\author{
Tatiana Begotti, Martina Bollo and Daniela Acquadro Maran * \\ Department of Psychology, Università di Torino Via Verdi, 10-10124 Torino, Italy; tatiana.begotti@unito.it (T.B.); \\ martina.bollo@unito.it (M.B.) \\ * Correspondence: daniela.acquadro@unito.it
}

Received: 28 July 2020; Accepted: 11 August 2020; Published: 12 August 2020

check for updates

\begin{abstract}
Aims: In the last decade, the use of smartphones, computers and devices has progressively increased, and prolonged use of technology and the internet has generated new arenas (and tools) for victimization. The first aim of this study was to analyze the use of coping strategies in young adult self-declared victims of cyberstalking. The coping strategies were categorized as proactive behavior, avoidance tactics and passivity. To better understand these strategies, they were analyzed in light of the experience of victimization in terms of incurred misconduct. The second aim was to analyze the coping strategies and the consequences (in terms of depression and anxiety) that occurred in victims; a comparison was made between males and females. Methods: A self-administered questionnaire was distributed to over 433 young adults living in Italy. The questionnaires were filled out by $398(92 \%)$ subjects, $41 \%$ males and 59\% females. Their ages ranged from 18 to 30 years $(M=23.5, S D=2.76)$. Respondents took part on a voluntary basis and did not receive any compensation (or extra credit) for their participation. Results: Findings from this investigation confirmed that among victims, females were more prone than males to experience cyberstalking (respectively, $65 \%$ and $35 \%$ ), with females experiencing a higher percentage of more than one form of cyberstalking behavior than males. Young adult male victims used the internet principally for online gaming, and for this activity, they experienced more cyberstalking behavior than females. In most cases, the perpetrator was a male, and the victim-cyberstalker relationship was a friendship or an acquaintance. For the coping strategies adopted, the findings indicated that the victims were more prone to use avoidance tactics than proactivity behavior and passivity strategies. Young adults involved in this investigation mainly used avoidance tactics to cope with the stressful situation, which implies that they preferred to decrease the use of the internet or stop online contact than collect evidence and try to contact and reason with the cyberstalker or increase the misuse of alcohol of psychotropic substances. Moreover, females were less prone to use proactive behavior than expected. Our findings suggested that males were more prone than females to adopt passivity strategies, while females were more prone to adopt avoidance tactics. Moreover, the data showed that proactivity behavior was adopted more in the case of online contacts and online identity fraud, while passivity strategies were adopted in the case of online threats. Conclusion: Findings from this investigation show the importance of improving the knowledge about the coping strategies that could be suggested to victims and the impact on their psychological health.
\end{abstract}

Keywords: coping strategies; cyberstalking; young adults; harassment; gender difference; depression; anxiety 


\section{Introduction}

In the last decade, the use of smartphones, computers and devices has progressively increased. In Europe, findings from the Eurostat Report [1] showed that 91\% of young people made daily use of the internet. The most common activities were to send and receive e-mails (86\%), to participate in social networking activities (83\%), to call and video chat $(50 \%)$ and to upload content such as photos, videos and text (47\%). These findings are in accordance with those of Alexi and colleagues [2], which affirmed that young adults are more prone than others to use internet and social networks mainly to increase social contact, play games and stay in touch with parents and friends. According to Hensler-McGinnis [3], prolonged use of technology and the internet has also generated new arenas (and tools) for victimization. Findings on online harassment from the Pew Research Center. [4] have shown that the phenomenon is more prevalent in social networking sites or apps $(66 \%)$, website comment sections (22\%), gaming (16\%), email (16\%), discussion sites and forums (10\%) and dating apps or websites $(6 \%)$. Among victims, young adults experience more cyberstalking than other forms of cyber violence, while young men are more prone than others to experience violence in online gaming.

An interesting issue is cyberstalking, which is a form of stalking (one of the most common forms of interpersonal violence [5]) found throughout technologies. Cyberstalking has been defined as "the repeated pursuit ( 2 or more times), by the same person, of an individual using communication technologies that causes the individual to experience a substantial emotional response or feel fear for their safety or the safety of someone close to them" [6]. This definition gives the boundaries of the phenomenon: the repetition of the pursuit, the intention to cause an emotional response, and the fear for the victim's or others' safety. Moreover, this definition introduces the novelty aspect of the technologies, which distinguishes it from the offline repetition of repetitive unwanted behaviors such as face to face intrusive communication, direct forms of surveillance and visual or physical proximity. Regarding the prevalence of the phenomenon, the investigation conducted by Sheridan and Grant [7] showed that $47.5 \%$ of 1051 self-defined stalking victims reported harassment via the internet. Findings from the investigation by Reyns and colleagues [8] showed that $40.8 \%$ of the participants in their survey had experienced cyberstalking victimization. Dressing and colleagues [9] found that among 6379 participants, the prevalence of cyberstalking was 6.3\%. Data from the European Union Agency for Fundamental Rights (FRA) survey. Reference [10] showed that female victims of cyberstalking (stalking by means of email, text messages or the internet) made up $4 \%$ of all 18- to 29 -year-old women in the EU. Short and colleagues [11] analyzed data from 353 self-defined victims of stalking and found that the majority of the victims were female (240) between the ages of 20 and 39 (58.6\%). In a previous study conducted by two of the authors of this work [12,13] that involved 107 young adult self-declared victims of cyberstalking, the findings showed that the victims were mainly females (61\%). Similar findings were found by Fissel [14]; among the sample of 1500 participants in her survey, 31.8\% were identified as victims of cyberstalking victimization, and women comprised the majority of the sample (69\%). This investigation demonstrated that the victimization experience caused emotional, psychological (e.g., anxiety and depression [15]), physical (e.g., sleep disturbance, panic attack, tiredness), social (e.g., damaged reputation) and economic (e.g., purchasing control systems) consequences. The results indicated that the victims experienced a higher level of depression and anxiety than those who had never experienced cyberstalking. In particular, anxiety and depression were expressed by victims that experienced both cyberstalking and offline violence. In the investigation conducted by Fissel and Reyns [6], their findings showed that the impact of cyberstalking in their sample of 477 cyberstalking victims was related to health $(61 \%)$, social (51\%), work $(48 \%)$ and school $(41 \%)$ consequences.

For this reason, the coping mechanisms used by victims with this phenomenon are particularly important. The adoption of an appropriate coping strategy (e.g., sought help from a social network administrator) could determine the termination of the stalking campaign [16]. In particular, in young adult victims of cyberstalking, the importance of intervention is linked to the need to limit the consequences of the victimization, which could determine its effects on social relations and occupational activities [11]. Findings from the investigation by Sheridan and Grant [7] indicated that victims of 
cyberstalking were more likely to keep evidence of their victimization, and they were more likely to report to police thanks to this coping strategy. In an investigation by Alexy et al. [2], most of the victims (75\%) chose to tell their experience to close friends, $54 \%$ told it to a family member and $11 \%$ did not tell anyone. Moreover, findings from the Amar and Alexi [17] survey showed that victims adopted a myriad of strategies to solve the problem. The coping strategies in the stalking and cyberstalking phenomenon were categorized by Spitzberg and Cupach [18,19] as Moving Toward (the victim is engaged in activities to negotiate the cessation of the unwanted behavior, for example, suggesting a new type of relationship), Moving Against (the victim threatens the cyberstalker, for example, calling the police if the behavior does not stop), Moving Away (the victim changes their habits, for example, changing email addresses), Moving Inward (the victim tries to handle the distress caused by the victimization experience by denying or distracting themselves, for example, using drugs) and Moving Outward (the victim solicits informal or formal assistance provided by third-parties, such as police). Some of these strategies were described as more or less useful than others: for example, the Moving Toward strategy could be interpreted by the persecutor as an invitation for future interaction [18]. In an investigation by Podanà and Imriskova [20], Spitzberg and Cupach's coping strategies were categorized as three types of general strategies: proactive behavior, avoidance tactics and passivity. Proactive behavior has been defined as coping strategies used by victims to solve the situation, such as meeting the cyberstalker face to face, reporting their victimization to third parties and seeking informal or formal help. This strategy is a mixture of coping strategies as categorized by Spitzberg and Cupach [18,21], and it comprises, for example, Moving Against and Moving Outward strategies. Avoidance tactics are referred to as behaviors adopted by victims to cope with the situation by changing their routine and usual activities, for example, the commute to work/home, and deterring the persecutor (for example, closing the own Facebook profile or limiting the view of the Facebook profile). These tactics are in accordance with Spitzberg and Cupach's $[18,21]$ Moving Away coping strategy. The third strategy described by Podaná and Imríšková [20] was passivity. With this strategy, the victim ignores the persecutor, denies the victimization or uses a distraction to not think about the stressful situation. This coping strategy was described by Spitzberg and Cupach [18,21] as Moving Inward. In their investigation, Podaná and Imríšková [20] found that among 147 victims, 47\% indicated the use of proactive behavior, $30 \%$ avoidance tactics and $23 \%$ passivity. In young adults, previous investigations suggested that this population usually tried to stop the stalking by themselves [22-24], for example, victims tended to change their habits and/or social environment (avoidance tactics). These coping strategies could have an economic and financial cost, due, for example, to a change in service provider. The request by the victim to the persecutor to stop the misconduct (proactive behavior) was used more by female victims than by male victims [23], even if they tended not to contact health care providers or to search for help in counselling services or from the police [22-28]. In their meta-analysis, Littleton and colleagues [29], regarding coping and health, found an association between denying (passivity strategies), distress and poorer health among young adults [30]. Moreover, these coping strategies were associated with less ability to use psychological adjustment among female stalking victims [31]. Kraaij and colleagues [32] found that both passive strategies and proactive behavior were associated with higher symptom levels of depression and anxiety. A possible explanation was that trying to solve a problem did not guarantee success in stopping the misconduct and this, in turn, may increase the victim's distress. Furthermore, the use of proactive behavior may lead to an increase in distress due to the need, for example, to meet the persecutor.

The first aim of this study was to analyze the use of coping strategies in young adult self-declared victims of cyberstalking. The coping strategies were categorized as proactive behavior, avoidance tactics and passivity in accordance with the proposal made by Podaná and Imríšková [20]. To better understand these strategies, the coping strategies were analyzed in light of the experience of victimization in terms of incurred misconduct. The second aim was to analyze the coping strategies and the consequences (in terms depression and anxiety) that occurred in victims. In accordance with the literature [11-14], to better understand the impact of the cyberstalking behavior, a comparison was made between 
genders (males and females). The target population was young adults because, as suggested by Alexi and colleagues [2] and Lenhart and colleagues [4], they are more at risk of cyberstalking victimization than other individuals. The hypotheses were as follows:

i. Young adult victims of cyberstalking were more prone to use proactive behavior than avoidance tactics and passivity strategy;

ii. $\quad$ Females were more prone than males to use proactive behavior;

iii. The use of coping strategies had an impact on victims' well-being by increasing anxiety and depression, especially in those females that used passivity strategies.

\section{Materials and Methods}

\subsection{Participants}

A self-administered questionnaire was distributed to over 433 young adults living in Italy. The questionnaires were filled out by 398 (92\%) subjects, 41\% males and 59\% females. Their ages ranged from 18 to 30 years $(\mathrm{M}=23.5, \mathrm{SD}=2.76)$. Respondents took part on a voluntary basis and did not receive any compensation (or extra credit) for their participation.

\subsection{Measures}

The prevalence of cyberstalking was investigated using the scale developed by Reyns, Henson and Fisher [8]. The questions about cyberstalking were preceded by the description of the phenomenon by Spitzberg and Hoobler [15] and that by Galeazzi and Curci [33]: "Cyberstalking is defined as a set of threatening and/or harassing repeated behaviours aimed at searching, controlling, hacking personal information, and damaging an individual's reputation through the use of online communication tools: e-mail, blog, social network, chatroom or other sites. Such undesirable behaviours are perceived by the victim as annoying, unwanted, or threatening to their own safety." This definition was already used in an Italian survey with university students $[12,13]$. Participants were asked if they experienced a cyberstalking conduct, such as online contact, harassment, threats of violence, unwanted sexual advances and identity fraud (for each type of behavior, there was an item; possible answers were yes/no). For each cyberstalking behavior, participants indicated the nature of the relationship (possible answers: intimate, friend/acquaintance, stranger) and (if known) the gender of the perpetrator. There was also a question about the frequency of the behavior (participants could indicate one of the following answers: one or more times a day, more than three times a week, once a week, once a month, less than once a month). This questionnaire was used in previous investigations on cyberstalking in an Italian sample [12,13]. Coping strategies were investigated using 15 items taken from the Italian version of the Questionnaire on Stalking [34]. On the basis of the model of Podanà and Imriskova [20], the different coping strategies were categorized as three types of general strategies: proactive behavior (e.g., collect evidence; try to contact and reason with cyberstalker), avoidance tactics (e.g., decrease use of the internet; stop the online contact) and passivity (e.g., increase the misuse of alcohol; increase the use of psychotropic substances). Each category included 4 items (possible answers: yes/no) with a range of 0-4. Depression was measured using the shortened Beck Depression Inventory (BDI) [35-37]. This scale consists of 13 items that allow the classification of depressive symptoms according to different levels of gravity: none or minimal depression (scores 0-4), mild depression (5-7), moderate depression $(8-15)$ or severe depression ( $>15$ ) (in this study, Cronbach's $\alpha$ was 0.83 ). Anxiety symptoms were measured using the State-Trait Anxiety Inventory (STAI) [38,39]. The scale consists of two forms (20 items each) that assess how participants feel at the present moment (STAIY1-state anxiety) and how they feel most of the time (STAIY2-trait anxiety). Total scores can range between 20 and 80; the threshold value considers predictive of anxiety symptoms and is 40 . The levels of severity are defined as follows: mild (from 40 to 50), moderate (from 51 to 60) and severe (>60). Cronbach's $\alpha$ values were 0.93 for STAIY1 and 0.92 for STAIY2. In the last part of the questionnaire, participants 
provided sociodemographic data, such as gender, age, education level, marital status and time spent in online activities.

\subsection{Procedure}

The local ethical committee of the University of Turin approved this research project (N.277326/2017). Two research assistants collected the data after project approval and specific training by the researchers. The questionnaires were given to 433 young adults. An information letter and the informed consent form were distributed to the participants in accordance with the Declaration of Helsinki. Completing the questionnaire took approximately $20 \mathrm{~min}$. The questionnaire was completed and returned immediately.

\subsection{Data Analysis}

Due the categorical nature of the data, $\chi^{2}$ tests were used to examine differences in the use of the internet and cyberstalking behavior, followed by effect-size calculations (Cramer's V) to estimate the statistical significance of the score differences. To determine which cell differences contributed to the $\chi^{2}$ test results, the standardized Pearson residuals (SPRs) were calculated for each cell. SPRs whose absolute values were greater than 1.96 indicated that the number of cases in that cell was significantly larger than would be expected with a significance level of 0.05 [40]. Descriptive measures were calculated (means $\pm \mathrm{SD}$ ), and ANOVA was performed to evaluate differences between groups. To calculate the estimate of the effect size, the eta-squared was calculated. Differences were considered statistically significant if $p<0.05$. Pearson bivariate correlations were performed to test the associations between variables. Data were processed using SPSS version 26 (IBM Corp., Armonk, NY, USA).

\section{Results}

\subsection{The Prevalence of Cyberstalking}

Within the total sample, 180 participants $(45.2 \%)$ were victims of cyberstalking (they had suffered at least one form of stalking). Among them, $117(65 \%)$ were females and $63(35 \%)$ were males. The mean age of the victims was 23.3 years $(\mathrm{SD}=2.42)$. A total of 101 participants $(25 \%)$ had been victims of cyberstalking through online contacts, 67 (17\%) through online harassment, $71(18 \%)$ through unwanted sexual advances online, $37(9 \%)$ through online threats of violence and $43(11 \%)$ through online identity fraud. The use of the internet for online gaming was referenced significantly more frequently by male than female victims $\left(x^{2}=16.92, p=0.002\right)$, in particular, for those males for whom the use of the internet for online gaming was ten hours or more per week (SPR $=|2.4|$, Cramer's $\mathrm{V}=0.31$ ). For other uses of the internet, there were no statistically significant differences on the basis of gender. Approximately $21.6 \%$ of male participants in the investigation experienced one cyberstalking behavior and $16.7 \%$ more than one. Approximately $22.6 \%$ of female participants experienced one cyberstalking behavior and $27.4 \%$ more than one $\left(\chi^{2}=7.20, p=0.027\right.$; SPR $=|2.5|$, Cramer's V $\left.=0.31\right)$. More details about the different forms of cyberstalking are reported in Table 1.

Table 1. The cyberstalking behavior.

\begin{tabular}{cccccc}
\hline & $\begin{array}{c}\text { Online } \\
\text { Contact } \\
(n=101)\end{array}$ & $\begin{array}{c}\text { Online } \\
\text { Harassment } \\
(n=67)\end{array}$ & $\begin{array}{c}\text { Online } \\
\text { Unwanted } \\
\text { Sexual } \\
\text { Advances } \\
(n=71)\end{array}$ & $\begin{array}{c}\text { Online Threats } \\
\text { of Violence } \\
(n=37)\end{array}$ & $\begin{array}{c}\text { Online Identity } \\
\text { Fraud } \\
(n=43)\end{array}$ \\
males & $26 \%$ & \multicolumn{5}{c}{ Victim's Gender } \\
females & $74 \%$ & $63 \%$ & $23 \%$ & $56 \%$ & $42 \%$ \\
\hline
\end{tabular}


Table 1. Cont.

\begin{tabular}{|c|c|c|c|c|c|}
\hline & $\begin{array}{l}\text { Online } \\
\text { Contact } \\
(n=101)\end{array}$ & $\begin{array}{l}\text { Online } \\
\text { Harassment } \\
\quad(n=67)\end{array}$ & $\begin{array}{c}\text { Online } \\
\text { Unwanted } \\
\text { Sexual } \\
\text { Advances } \\
(n=71)\end{array}$ & $\begin{array}{l}\text { Online Threats } \\
\text { of Violence } \\
(n=37)\end{array}$ & $\begin{array}{c}\text { Online Identity } \\
\text { Fraud } \\
(n=43)\end{array}$ \\
\hline \multicolumn{6}{|c|}{ Perpetrator's Gender } \\
\hline male & $75 \%$ & $75 \%$ & $87 \%$ & $69 \%$ & $63 \%$ \\
\hline female & $25 \%$ & $25 \%$ & $13 \%$ & $31 \%$ & $37 \%$ \\
\hline \multicolumn{6}{|c|}{ Relationship with the Perpetrator } \\
\hline $\begin{array}{c}\text { friend or } \\
\text { acquaintance }\end{array}$ & $45 \%$ & $52 \%$ & $47 \%$ & $58 \%$ & $28 \%$ \\
\hline $\begin{array}{l}\text { partner or } \\
\text { ex-partner }\end{array}$ & $26 \%$ & $14 \%$ & $4 \%$ & $17 \%$ & $10 \%$ \\
\hline Stranger & $29 \%$ & $34 \%$ & $49 \%$ & $25 \%$ & $62 \%$ \\
\hline \multicolumn{6}{|c|}{ Different Uses of the Internet } \\
\hline $\begin{array}{l}\text { Stay in contact with } \\
\text { relatives/friends }\end{array}$ & $64 \%$ & $57 \%$ & $64 \%$ & $60 \%$ & $53 \%$ \\
\hline Study/Work & $28 \%$ & $35 \%$ & $24 \%$ & $40 \%$ & $47 \%$ \\
\hline Flirt & $3 \%$ & $0 \%$ & $4 \%$ & $0 \%$ & $0 \%$ \\
\hline Other motives & $5 \%$ & $8 \%$ & $8 \%$ & $0 \%$ & $0 \%$ \\
\hline \multicolumn{6}{|c|}{ Time Spent on the Internet ${ }^{1}$ (More than $3 \mathrm{~h}$ a Day) } \\
\hline Leisure & $54 \%$ & $59 \%$ & $58 \%$ & $60 \%$ & $45 \%$ \\
\hline Send messages & $42 \%$ & $42 \%$ & $43 \%$ & $44 \%$ & $50 \%$ \\
\hline Chat & $43 \%$ & $42 \%$ & $41 \%$ & $47 \%$ & $43 \%$ \\
\hline Videogames & $8 \%$ & $14 \%$ & $7 \%$ & $9 \%$ & $5 \%$ \\
\hline
\end{tabular}

${ }^{1}$ Total percentages are over $100 \%$ because the different activities are not mutually exclusive.

\subsection{Coping Strategies}

In Table 2 are reported the means of the three categories of coping strategies in the total sample of victims.

Table 2. Coping strategies used in the sample of victims $(n=180)$.

\begin{tabular}{cccc}
\hline & $\begin{array}{c}\text { Proactive } \\
\text { M (SD) }\end{array}$ & $\begin{array}{c}\text { Avoidance } \\
\text { M (SD) }\end{array}$ & $\begin{array}{c}\text { Passivity } \\
\text { M (SD) }\end{array}$ \\
\hline Coping strategies & $0.97(1.02)$ & $1.27(0.84)$ & $0.19(0.55)$ \\
\hline \multicolumn{4}{c}{ Notes: M, mean; SD, standard deviation; (Range: $0-4)}$.
\end{tabular}

As we can see in Table 2, victims had a greater tendency to use avoidance coping strategies, followed by proactive coping and finally passivity strategies. One-way ANOVA was performed to compare males $(n=63)$ vs. females $(n=117)$. (Table 3$)$.

Table 3. Coping strategies: comparison on the basis of gender (one-way ANOVA).

\begin{tabular}{cccccc}
\hline & $\begin{array}{c}\text { Males } \\
\text { M (SD) }\end{array}$ & $\begin{array}{c}\text { Females } \\
\text { M (SD) }\end{array}$ & F & $p$ & $\boldsymbol{\eta}^{2}$ \\
\hline Proactive coping & $0.93(0.96)$ & $1.01(1.07)$ & 0.22 & n.s. & 0.002 \\
\hline Avoidance coping & $1.09(0.89)$ & $1.39(0.79)$ & 4.69 & 0.03 & 0.03 \\
\hline Passivity coping & $0.33(.076)$ & $0.11(0.37)$ & 6.16 & 0.01 & 0.04 \\
\hline \multicolumn{6}{c}{ Notes: M, mean; SD, standard deviation; (Range: 0-4). }
\end{tabular}


As we can observe in Table 3, the propensity to use avoidance coping strategies was greater in females, while the tendency to use passivity coping strategies was greater in males. No significant differences on the basis of gender were found with respect to proactive coping strategies.

To analyze the use of different coping strategies on the basis of the different forms of cyberstalking, one-way ANOVA was performed. Coping strategies were introduced as dependent variables, while victims of each form of cyberstalking were compared, one by one, with all the other victims. The results are reported in Table 4.

Table 4. Coping strategies: comparison on the basis of different forms of cyberstalking (one-way ANOVA).

\begin{tabular}{|c|c|c|c|c|c|}
\hline & $\begin{array}{l}\text { Online Contacts }(n=87) \\
\text { M (SD) }\end{array}$ & $\begin{array}{l}\text { Others } \\
(n=93) \\
\text { M (SD) }\end{array}$ & $\mathbf{F}$ & $p$ & $\eta^{2}$ \\
\hline Proactive coping & $1.25(1.07)$ & $0.63(0.86)$ & 15.17 & 0.000 & 0.09 \\
\hline Avoidance coping & $1.38(0.84)$ & $1.13(0.84)$ & 3.29 & n.s. & 0.02 \\
\hline \multirow[t]{2}{*}{ Passivity coping } & $0.24(0.60)$ & $0.13(0.48)$ & 1.54 & n.s. & 0.01 \\
\hline & $\begin{array}{l}\text { Online harassment }(n=61) \\
M \text { (SD) }\end{array}$ & $\begin{array}{c}\text { Others } \\
(n=119) \\
M(S D)\end{array}$ & $\mathbf{F}$ & $p$ & $\eta^{2}$ \\
\hline Proactive coping & $1.13(1.24)$ & $0.88(0.85)$ & 2.17 & n.s. & 0.01 \\
\hline Avoidance coping & $1.34(0.87)$ & $1.22(0.83)$ & 0.75 & n.s. & 0.005 \\
\hline \multirow[t]{2}{*}{ Passivity coping } & $0.22(0.57)$ & $0.17(0.54)$ & 0.29 & n.s. & 0.002 \\
\hline & $\begin{array}{c}\text { Online Advances }(n=64) \\
\text { M (SD) }\end{array}$ & $\begin{array}{c}\text { Others } \\
(n=116) \\
M(S D)\end{array}$ & $\mathbf{F}$ & $p$ & $\eta^{2}$ \\
\hline Proactive coping & $1.14(1.02)$ & $0.85(1.00)$ & 2.98 & n.s. & 0.02 \\
\hline Avoidance coping & $1.42(0.74)$ & $1.18(0.91)$ & 3.05 & n.s. & 0.02 \\
\hline \multirow[t]{2}{*}{ Passivity coping } & $0.17(0.48)$ & $0.20(0.60)$ & 0.14 & n.s. & 0.001 \\
\hline & $\begin{array}{c}\text { Online Threats }(n=37) \\
\text { M (SD) }\end{array}$ & $\begin{array}{c}\text { Others } \\
(n=143) \\
M(S D)\end{array}$ & $\mathbf{F}$ & $p$ & $\eta^{2}$ \\
\hline Proactive coping & $1.14(1.29)$ & $0.91(0.91)$ & 1.32 & n.s. & 0.009 \\
\hline Avoidance coping & $1.27(0.90)$ & $1.27(0.84)$ & 0.000 & n.s. & 0.000 \\
\hline \multirow[t]{2}{*}{ Passivity coping } & $0.41(0.76)$ & $0.12(0.45)$ & 8.07 & 0.005 & 0.05 \\
\hline & $\begin{array}{l}\text { Online Identity Fraud }(n=37) \\
\text { M (SD) }\end{array}$ & $\begin{array}{c}\text { Others } \\
(n=143) \\
M(S D)\end{array}$ & $\mathbf{F}$ & $p$ & $\eta^{2}$ \\
\hline Proactive coping & $1.27(1.24)$ & $0.89(0.94)$ & 3.93 & 0.04 & 0.03 \\
\hline Avoidance coping & $1.29(0.87)$ & $1.26(0.84)$ & 0.02 & n.s. & 0.000 \\
\hline Passivity coping & $0.23(0.58)$ & $0.18(0.55)$ & 0.28 & n.s. & 0.002 \\
\hline
\end{tabular}

Notes: M, mean; SD, standard deviation (Range: 0-4).

Although avoidance coping strategies had the highest mean levels for all the categories of cyberstalking, some differences were found in the case of proactive and passivity coping strategies. As we can observe in Table 4, there was a greater tendency to use proactive coping strategies by victims of online contacts and of online identity fraud, compared to victims of other forms of cyberstalking. Moreover, a significant difference was found in the case of victims of online threats, who had a greater propensity to use of passivity coping strategies compared to victims of other forms of cyberstalking. 


\subsection{Depressive Symptoms}

Approximately $65 \%$ of the total sample had a minimal score on the Beck Depression Inventory (BDI). The rest of the sample had a mild (16.3\%), moderate (14.6\%) or severe score $(4.1 \%)$ for depressive symptoms. One-way ANOVA was performed to compare males and females, introducing the BDI scale as dependent variable. No significant differences were found $(\mathrm{F}=0.89 ; \mathrm{df}=1 ; p=0.35)$.

Victims of cyberstalking (subjects who had suffered at least one form of cyberstalking; $n=180$ ) were compared to subjects who have never been victims of stalking (not victims; $n=218$ ). One-way ANOVA was performed to compare victims and not victims. The BDI scale was introduced as the dependent variable (Table 5).

Table 5. Depressive symptoms: comparison between not victims and victims (one-way ANOVA).

\begin{tabular}{lccccc}
\hline & $\begin{array}{c}\text { Not Victims } \\
\text { M (SD) }\end{array}$ & $\begin{array}{c}\text { Victims } \\
\text { M (SD) }\end{array}$ & F & $p$ & $\eta^{2}$ \\
\hline Depressive symptoms & $3.45(3.76)$ & $4.68(4.83)$ & 7.28 & 0.007 & 0.02 \\
\hline
\end{tabular}

Notes: M, mean; SD, standard deviation; F, Fisher's ratio; n.s., not statistically significant. (Range: $0-39$ ).

As we can see in Table 5, the mean of depressive symptoms was significantly higher in victims of cyberstalking than in those who were not victims.

\subsection{Anxiety Symptoms}

Among the total sample, $45.3 \%$ of subjects scored under 40 for the STAIY1 (the threshold value considered predictive of state anxiety symptoms); $31.2 \%$ of the participants reported a mild level of anxiety, $13.8 \%$ a moderate level and the rest $(9.7 \%)$ a severe level. For trait anxiety symptoms, $39.2 \%$ of participants scored under 40 for the STAIY2; 36.3\% recorded a mild score, $17.2 \%$ a moderate score and the rest $(7.3 \%)$ a severe trait anxiety score. Two one-way ANOVAs were performed to compare males and females, introducing the STAIY1 and STAIY2 scales as dependent variables. No significant differences were found on trait anxiety $(\mathrm{F}=1.01 ; \mathrm{df}=1 ; p=0.30)$, while females reported a higher level of state anxiety $($ mean $=43.67 ; \mathrm{s} . \mathrm{d} .=12.12)$ than males $($ mean $=40.18 ; \mathrm{s} . \mathrm{d} .=10.62)(\mathrm{F}=8.07 ; \mathrm{df}=1$; $p=0.005)$.

One-way ANOVA was performed to compare subjects who were never involved in a cyberstalking behavior (not victims; $n=218$ ) with victims of cyberstalking (victims; $n=180$ ). The State-Trait Anxiety Inventory scales, versions 1 (STAIY1) and 2 (STAIY2), were introduced as the dependent variables (Table 6).

Table 6. State-trait anxiety symptoms: comparison between not victims and victims (one-way ANOVA).

\begin{tabular}{cccccc}
\hline & $\begin{array}{c}\text { Not Victims } \\
\text { M (SD) }\end{array}$ & $\begin{array}{c}\text { Victims } \\
\text { M (SD) }\end{array}$ & F & $p$ & $\eta^{2}$ \\
\hline State Anxiety symptoms & $41.51(11.23)$ & $43.10(12.05)$ & 1.68 & n.s. & 0.005 \\
\hline Trait Anxiety symptoms & $42.27(10.75)$ & $44.14(10.61)$ & 2.82 & n.s. & 0.008 \\
\hline Notes: M, mean; SD, standard deviation; F, Fisher's ratio; n.s., not statistically significant. (Range: 20-80).
\end{tabular}

As reported in Table 6, the means of the state and trait anxiety symptoms were not significantly different in victims and not victims of cyberstalking.

\subsection{Relationships between Coping Strategies, Depression and Anxiety}

To evaluate the relation of the different forms of coping strategies with depression and anxiety, Pearson bivariate correlations were performed in the sample of victims. The results are reported in Table 7. 
Table 7. Coping strategies, depression, anxiety: Pearson bivariate correlations in victims $(n=180)$.

\begin{tabular}{ccccc}
\hline & BDI & STAIY1 & STAIY2 \\
\cline { 2 - 5 } & Proactive coping & 0.09 & 0.06 & 0.06 \\
Avoidance coping & 0.15 & 0.13 & 0.06 \\
Passivity coping & $0.39 * *$ & $0.17^{*}$ & $0.25^{* *}$ \\
\cline { 2 - 4 } & * The correlation is significant at the 0.05 level. ${ }^{* *}$ The correlation is significant at the 0.01 level.
\end{tabular}

As we can observe in Table 7, there was a significant and positive association between passivity coping strategies, depressive symptoms and state and trait anxiety. The same Pearson bivariate correlations were performed separately in female and male victims.

As we can observe in Table 8, there was a significant and positive association between passivity coping strategies, depressive symptoms and state and trait anxiety. In particular, the greater use of passivity coping was positively associated with depressive symptoms regardless of gender and state and trait anxiety symptoms in the case of female victims.

Table 8. Coping strategies, depression, anxiety: Pearson bivariate correlations in female $(n=117)$ and male $(n=63)$ victims.

\begin{tabular}{cccc}
\hline & BDI & STAIY1 & STAIY2 \\
\hline & FEMALES/MALES & FEMALES/MALES & FEMALES/MALES \\
Proactive coping & $0.13 / 0.02$ & $0.01 / 0.18$ & $0.05 / 0.12$ \\
Avoidance coping & $0.19 / 0.10$ & $0.12 / 0.17$ & $0.09 / 0.09$ \\
Passivity coping & $0.48^{* *} / 0.39^{* *}$ & $0.29^{* *} / 0.098$ & $0.39 * * 0.12$ \\
\hline${ }^{*}$ The correlation is significant at the 0.05 level. ${ }^{* *}$ The correlation is significant at the 0.01 level.
\end{tabular}

\section{Discussion}

The aim of this work was to describe the coping strategies adopted by young adult self-declared victims of cyberstalking. As described below, this phenomenon mainly affects young adults since they are more prone than others to use the internet and technology to keep in touch with friends and relatives [1,2]. As a consequence, they are also more prone than others to be victims of some forms of violence. When the misconduct is repeated over time and the persecutor intentionally causes the victim to have a feeling of fear (for their safety or for others close to victim), the phenomenon is called cyberstalking.

Findings from this investigation confirmed that among victims, females were more prone than males to experience cyberstalking (respectively, 65\% and 35\%) [11,14], with females experiencing a higher percentage of more than one form of cyberstalking behavior than males. Young adult male victims used the internet principally for online gaming, and for this activity, they experienced more cyberstalking behavior than females (these latest data confirmed the results of Lenhart and colleagues [4]). In most cases, the perpetrator was a male, and the victim-cyberstalker relationship was a friendship or an acquaintance. For the coping strategies adopted, the findings indicated that the victims were more prone to use avoidance tactics than proactivity behavior and passivity strategies, confirming the results from Amar and colleagues [22] and not those from Podanà and Imriskova [20]. Thus, hypothesis 1 of the present study was not confirmed. Young adults involved in this investigation mainly used avoidance tactics to cope with the stressful situation, which implies that they preferred to decrease the use of the internet or stop online contact than collect evidence and try to contact and reason with the cyberstalker or increase the misuse of alcohol of psychotropic substances. Moreover, females were less prone to use proactive behavior than expected. According to Bjerregaard [23], our hypothesis was that females were more prone than males to use these coping strategies; however, our findings did not support this hypothesis. Our findings suggested that males were more prone than females to adopt passivity strategies, while females were more prone to adopt avoidance tactics. An interesting 
finding was about the relationship among cyberstalking behavior and coping strategies adopted by victims. The data showed that proactivity behavior was adopted more in the case of online contacts and online identity fraud, while passivity strategies were adopted in the case of online threats.

This is very interesting because it gives us some suggestions about prevention. It would be useful, for example, to direct information campaigns or law enforcement not only toward the importance of the request for help but also including the message that some coping strategies could be used effectively to cope with cyberstalking behavior.

As found in this investigation, the use of a coping strategy could increase psychological consequences, such as depression and anxiety. Both depression and anxiety symptoms scores were similar among victims and non-victims: Victims had a score that indicates minimal or not to mild depression symptoms, while both victims and non-victims indicated minimal or not to mild anxiety symptoms. Confirming previous studies [12,13], victims were more prone that non-victims to suffer depression symptoms. In particular, the use of passivity strategies increased depression and state and trait anxiety symptoms. In light of gender differences, both males and females suffered depression symptoms when they used passivity strategies [29,32], and in females, these strategies were also related to state and trait anxiety symptoms. Thus, the third hypothesis was confirmed. This suggests, once again, that it is fundamental to improve the coping ability of victims of cyberstalking. According to McKeon, McEwan and Luebbers [41] and Chan and Sheridan [42], they could not perceive the cyberstalking as a serious behavior that has an impact in their life or could have poor health $[6,15]$, social, work and school consequences.

This investigation has some limitations. The first involves the cross-sectional nature of the investigation; the sample was not randomly selected. For this reason, the results should be taken with caution and should not be generalized. Moreover, the findings showed that the majority of the victims were females, while the cyberstalkers were males. The nature of the perpetrator-victim relationship was not investigated, nor was sexual orientation. For example, the aim to re-establish a romantic relationship could be one of the reasons for the cyberstalking behavior and, as suggested by Derlega and colleagues [43], men are more prone than women to harass with this motivation. Future research could investigate the nature of the victim-cyberstalker relationship, the cyberstalking behavior and the coping strategies adopted by the victims. Furthermore, the group considered as not victims included all subjects who have never been victims of cyberstalking; we did not analyze the characteristics and profile of these subjects and cannot exclude that they were involved in the phenomenon in such a way and that also perpetrators belonged to this group. Moreover, other elements (such as family situation, income stability, parent support) that could influence the use of coping strategies were not investigated. In particular, in an investigation in cyberstalking by Wright [44], an association between social support and depression was found. Future research has to investigate the influence of these elements to better understand the type of coping strategies used and the social environment. Furthermore, to better understand the success in stopping cyberstalking, future research could investigate victims' satisfaction in the use of coping strategies in relation to the behavior of the perpetrator. Another limitation involves the bias linked to socially desirable responding, that is, the tendency to reply to questionnaire items by giving a favorable image of oneself. This bias is possible whenever the aim of the research project is about victimization: Traditionally, men are less prone than women to indicate that they have been victimized, both in cyberstalking and in other phenomena that involve a form of violence $[45,46]$. Thus, future research could use a tool to investigate the social desirability issue [47].

Overall, in conclusion, from this investigation emerges the finding that both the prevention of the phenomenon and the intervention in the case of victimization are important to permit young adults to stop cyberstalking as soon as possible. From the first online unwanted approach and contact, for example, it is possible to stop the behavior before it becomes a repetitive and intrusive conduct that causes negative feelings [48-50]. The prevention includes flyers in cafeterias, internet cafés, hangouts and meeting places frequented by young adults. Advertisements on social networking sites and websites could also be useful. The content could address those behaviors that are lawful and those 
that may be suspect or reportable. Flyers and advertisements could also explain the prevalence of the phenomenon, who, generally, the victims and the perpetrators are and how to cope with cyberstalking. Addressing intervention could be useful for victims to help them cope with the consequences of cyberstalking, to improve their psychological health, to understand the source of the distressful situation and to manage the perpetrator and the relationship with them [51,52]. The hope is that the findings from this investigation could be useful to all practitioners that have a role in the prevention and intervention with cyberstalker victims, to improve the knowledge about the coping strategies that could be suggested to victims and the impact on their psychological health.

Author Contributions: Conceptualization, T.B. and D.A.M.; data curation, T.B.; formal analysis, T.B. and M.B.; investigation, T.B. and D.A.M.; methodology, T.B. and M.B.; project administration, T.B. and D.A.M.; supervision, T.B. and D.A.M.; writing, T.B. and D.A.M. All authors have read and agreed to the published version of the manuscript.

Funding: This research received no external funding.

Conflicts of Interest: The authors declare no conflict of interest.

\section{References}

1. Eurostat Statistics Explained. Being Young in Europe Today-Digital World. Available online: https://ec.europa.eu/eurostat/statistics-explained/index.php/Being_young_in_Europe_today_-_digital_ world\#Information_and_communications_technology_skills (accessed on 15 December 2017).

2. Alexy, E.M.; Burgess, A.W.; Baker, T.; Smoyak, S.A. Perceptions of cyberstalking among college students. Brief Treat. Crisis Interv. 2005, 5, 279. [CrossRef]

3. Hensler-McGinnis, N.F. Cyberstalking Victimization: Impact and Coping Responses in a National University Sample. Doctoral Dissertation, University of Maryland, Maryland, MA, USA, 5 May 2008.

4. Lenhart, A.; Smith, A.; Anderson, M.; Duggan, M.; Perrin, A. Teens, Technology E Friendship; Pew Research Center: Washington, DC, USA, 2015; Volume 10.

5. Worsley, J.D.; Wheatcroft, J.M.; Short, E.; Corcoran, R. Victims' voices: Understanding the emotional impact of cyberstalking and individuals' coping responses. Sage Open 2017, 7, 2158244017710292. [CrossRef]

6. Fissel, E.R.; Reyns, B.W. The aftermath of cyberstalking: School, work, social, and health costs of victimization. Am. J. Crim. Justice 2020, 45, 70-87. [CrossRef]

7. Sheridan, L.P.; Grant, T. Is cyberstalking different? Psychol. Crime Law 2007, 13, 627-640. [CrossRef]

8. Reyns, B.W.; Henson, B.; Fisher, B.S. Stalking in the twilight zone: Extent of cyberstalking victimization and offending among college students. Deviant Behav. 2012, 33, 1-25. [CrossRef]

9. Dreßing, H.; Bailer, J.; Anders, A.; Wagner, H.; Gallas, C. Cyberstalking in a large sample of social network users: Prevalence, characteristics, and impact upon victims. Cyberpsychol. Behav. Soc. Netw. 2014, 17, 61-67. [CrossRef] [PubMed]

10. European Union Agency for Fundamental Rights (FRA). Violence against Women Survey, Survey Data Explorer; Publications Office of the European Union: Luxembourg, 2014.

11. Short, E.; Guppy, A.; Hart, J.A.; Barnes, J. The impact of cyberstalking. Stud. Media Commun. 2015, 3, $23-37$. [CrossRef]

12. Begotti, T.; Acquadro Maran, D. Characteristics of Cyberstalking Behaviour, Consequences, and Coping Strategies: A Cross-Sectional Study in a Sample of Italian University Students. Future Internet. 2019, 11, 120. [CrossRef]

13. Acquadro Maran, D.; Begotti, T. Prevalence of Cyberstalking and Previous Offline Victimization in a Sample of Italian University Students. Soc. Sci. 2019, 8, 30. [CrossRef]

14. Fissel, E.R. Victimization of the 21st Century: An Examination of Cyberstalking Victimization Using a Target Congruence Approach. Doctoral Dissertation, University of Cincinnati, Cincinnati, OH, USA, 2019.

15. Spitzberg, B.H.; Hoobler, G. Cyberstalking and the technologies of interpersonal terrorism. New Media Soc. 2002, 4, 71-92. [CrossRef]

16. Villacampa, C.; Pujols, A. Effects of and coping strategies for stalking victimisation in Spain: Consequences for its criminalisation. Int. J. Law Crime Justice 2019, 56, 27-38. [CrossRef]

17. Amar, A.F.; Alexy, E.M. Coping with stalking. Issues Ment. Health Nurs. 2010, 31, 8-14. [CrossRef] [PubMed] 
18. Spitzberg, B.H.; Cupach, W.R. Paradoxes of Pursuit: Toward a Relational. In Stalking Crimes and Victim Protection: Prevention, Intervention, Threat Assessment, and Case Management; Routledge: Abingdon, UK, 2001; p. 97.

19. Cupach, W.R.; Spitzberg, B.H. Obsessive relational intrusion: Incidence, perceived severity, and coping. Violence and Victims 2000, 15, 357-372. [CrossRef]

20. Podaná, Z.; Imríšková, R. Victims' responses to stalking: An examination of fear levels and coping strategies. J. Interpers. Violence 2016, 31, 792-809. [CrossRef] [PubMed]

21. Cupach, W.R.; Spitzberg, B.H.; Silverman, W.H. The Dark Side of Relational Pursuit: From Attraction to Obsession and Stalking; Routledge: Abingdon, UK, 2004.

22. Amar, A.F. College women's experience of stalking: Mental health symptoms and changes in routines. Arch. Psychiatr. Nurs. 2006, 20, 108-116. [CrossRef] [PubMed]

23. Bjerregaard, B. An empirical study of stalking victimization. Violence Vict. 2000, 15, 389. [CrossRef]

24. Fisher, B.S.; Cullen, F.T.; Turner, M.G. Being pursued: Stalking victimization in a national study of college women. Criminol. Public Policy 2002, 1, 257-308. [CrossRef]

25. Fremouw, W.J.; Westrup, D.; Pennypacker, J. Stalking on campus: The prevalence and strategies for coping with stalking. J. Forensic Sci. 1997, 42, 666-669. [CrossRef]

26. Jordan, C.E.; Wilcox, P.; Pritchard, A.J. Stalking acknowledgement and reporting among college women experiencing intrusive behaviours: Implications for the emergence of a "classic stalking case". J. Crim. Justice 2007, 35, 556-569. [CrossRef]

27. Pathe, M.; Mullen, P.E. The impact of stalkers on their victims. Br. J. Psychiatry 1997, 170, 12-17. [CrossRef]

28. Thompson, C.M.; Stewart, A.L.; Dennison, S.M. Using dynamic contextual factors to better understand the etiology and escalation of stalking violence. Crim. Justice Behav. 2020, 47, 99-122. [CrossRef]

29. Littleton, H.; Horsley, S.; John, S.; Nelson, D.V. Trauma coping strategies and psychological distress: A meta-analysis. J. Trauma. Stress: Off. Publ. Int. Soc. Trauma. Stress Stud. 2007, 20, 977-988. [CrossRef] [PubMed]

30. Lawler, C.; Ouimette, P.; Dahlstedt, D. Posttraumatic stress symptoms, coping, and physical health status among university students seeking health care. J. Trauma. Stress: Off. Publ. Int. Soc. Trauma. Stress Stud. 2005, 18, 741-750. [CrossRef] [PubMed]

31. Kamphuis, J.H.; Emmelkamp, P.M.; Bartak, A. Individual differences in post-traumatic stress following post-intimate stalking: Stalking severity and psychosocial variables. Br. J. Clin. Psychol. 2003, 42, 145-156. [CrossRef] [PubMed]

32. Kraaij, V.; Arensman, E.; Garnefski, N.; Kremers, I. The role of cognitive coping in female victims of stalking. J. Interpers. Violence 2007, 22, 1603-1612. [CrossRef] [PubMed]

33. Galeazzi, G.M.; Curci, P. La sindrome del molestatore assillante (stalking): Una rassegna. G. Ital. Di Psicopatol. 2001, 7, 434-452. (In Italian)

34. Acquadro Maran, D.; Varetto, A.; Zedda, M.; Franscini, M. Health care professionals as victims of stalking: Characteristics of the stalking behaviour, consequences, and motivation in Italy. J. Interpers. Violence 2017, 32, 2605-2625. [CrossRef]

35. Beck, A.T.; Ward, C.; Mendelson, M. Beck Depression Inventory (BDI). Arch. Gen. Psychiatry 1961, 4, 561-571. [CrossRef]

36. Beck, A.T.; Beck, R.W. Screening depressed patients in family practice: A rapid technic. Postgrad. Med. 1972, 52, 81-85. [CrossRef]

37. Scilligo, P.F. La scala di depressione di Beck [Beck's Depression Inventory]. In Scale Psicologiche [Psychological Scales]; IFREP: Roma, Italy, 1992.

38. Spielberger, C.D. Manual for the State-Trait Anxiety Inventory STAI (form Y) ("Self-Evaluation Questionnaire"); Consulting Psychologists Press: Palo Alto, CA, USA, 1983.

39. Pedrabissi, L.; Santinello, M. Inventario Per l'ansia di «Stato» e di «Tratto»: Nuova Versione Italiana Dello STAI Forma Y: Manuale [State-Trait Anxiety Inventory: The Italian New Version of STAI Y Form]; Organizzazioni Speciali: Firenze, Italy, 1989.

40. Agresti, A. Categorical Data Analysis; John Wiley \& Sons Inc.: Hoboken, NJ, USA, 2002; pp. 267-313.

41. McKeon, B.; McEwan, T.E.; Luebbers, S. It's Not Really Stalking If You Know the Person: Measuring Community Attitudes That Normalize, Justify and Minimise Stalking. Psychiatry Psychol. Law. 2015, 22, 291-306. [CrossRef] 
42. Chan, H.C.; Sheridan, L. Is this stalking? Perceptions of stalking behaviour among young male and female adults in Hong Kong and Mainland China. J. Interpers. Violence 2017, 35, 3710-3734. [CrossRef] [PubMed]

43. Derlega, V.J.; Winstead, B.A.; Pearson, M.R.; Janda, L.J.; Lewis, R.J.; Dutton, L.B.; Ferrer, R.; Greene, K. Unwanted pursuit in same-sex relationships: Effects of attachment styles, investment model variables, and sexual minority stressors. Partn. Abuse. 2001, 2, 300-322. [CrossRef]

44. Wright, M.F. Cyberstalking victimization, depression, and academic performance: The role of perceived social support from parents. Cyberpsychol. Behav. Soc. Netw. 2018, 21, 110-116. [CrossRef]

45. Straus, M.A. The controversy over domestic violence by women. In Violence in intimate relationship; Sage: Thousand Oaks, CA, USA, 1999; pp. 17-44.

46. Langhinrichsen-Rohling, J. Controversies involving gender and intimate partner violence in the United States. Sex Roles 2010, 62, 179-193. [CrossRef]

47. Van de Mortel, T.F. Faking it: Social desirability response bias in self-report research. Aust. J. Adv. Nurs. 2008, 25, 40.

48. Sheridan, L.; Davies, G.; Boon, J. The course and nature of stalking: A victim perspective. Howard J. Crim. Justice 2001, 40, 215-234. [CrossRef]

49. MacKenzie, R.D.; James, D.V. Management and treatment of stalkers: Problems, options, and solutions. Behav. Sci. Law. 2011, 29, 220-239. [CrossRef]

50. Chirico, F.; Heponiemi, T.; Pavlova, M.; Zaffina, S.; Magnavita, N. Psychosocial risk prevention in a global occupational health perspective. A descriptive analysis. Int. J. Environ. Res. Public Health 2019, 16, 2470. [CrossRef]

51. Zaccagnino, M.; Cussino, M.; Callerame, C.; Civilotti, C.; Fernandez, I. Anorexia nervosa and EMDR: A clinical case. J. EMDR Pract. Res. 2017, 11, 43-53. [CrossRef]

52. Civilotti, C.; Cussino, M.; Callerame, C.; Fernandez, I.; Zaccagnino, M. Changing the Adult State of Mind with respect to Attachment: An exploratory study of the role of EMDR psycho-therapy. J. EMDR Pract. Res. 2019, 13, 176-186. [CrossRef]

(C) 2020 by the authors. Licensee MDPI, Basel, Switzerland. This article is an open access article distributed under the terms and conditions of the Creative Commons Attribution (CC BY) license (http://creativecommons.org/licenses/by/4.0/). 